\title{
Chest Tube Flutter Valve
}

National Cancer Institute

\section{Source}

National Cancer Institute. Chest Tube Flutter Valve. NCI Thesaurus. Code C106373.

A type of valve that connects to a chest tube and facilitates the drainage of fluid, air, and other materials out of the pleural cavity, while not permitting the flow back into the pleural cavity. The valve "flutters" to open in one direction only. 